Made available courtesy of Slack, Inc: http://www.slackinc.com/

Slack, Inc. requests that interested viewers (Scholars and Researchers) understand that these articles can be accessed for their personal and reference use. The articles should not be reproduced in large quantities for distribution in classrooms or seminars without obtaining the rights from Slack Incorporated. Slack, Inc. provides licensed reprints for distribution purposes for an appropriate fee.

\title{
Helping Older Adults Find Meaning and Purpose Through Storytelling
}

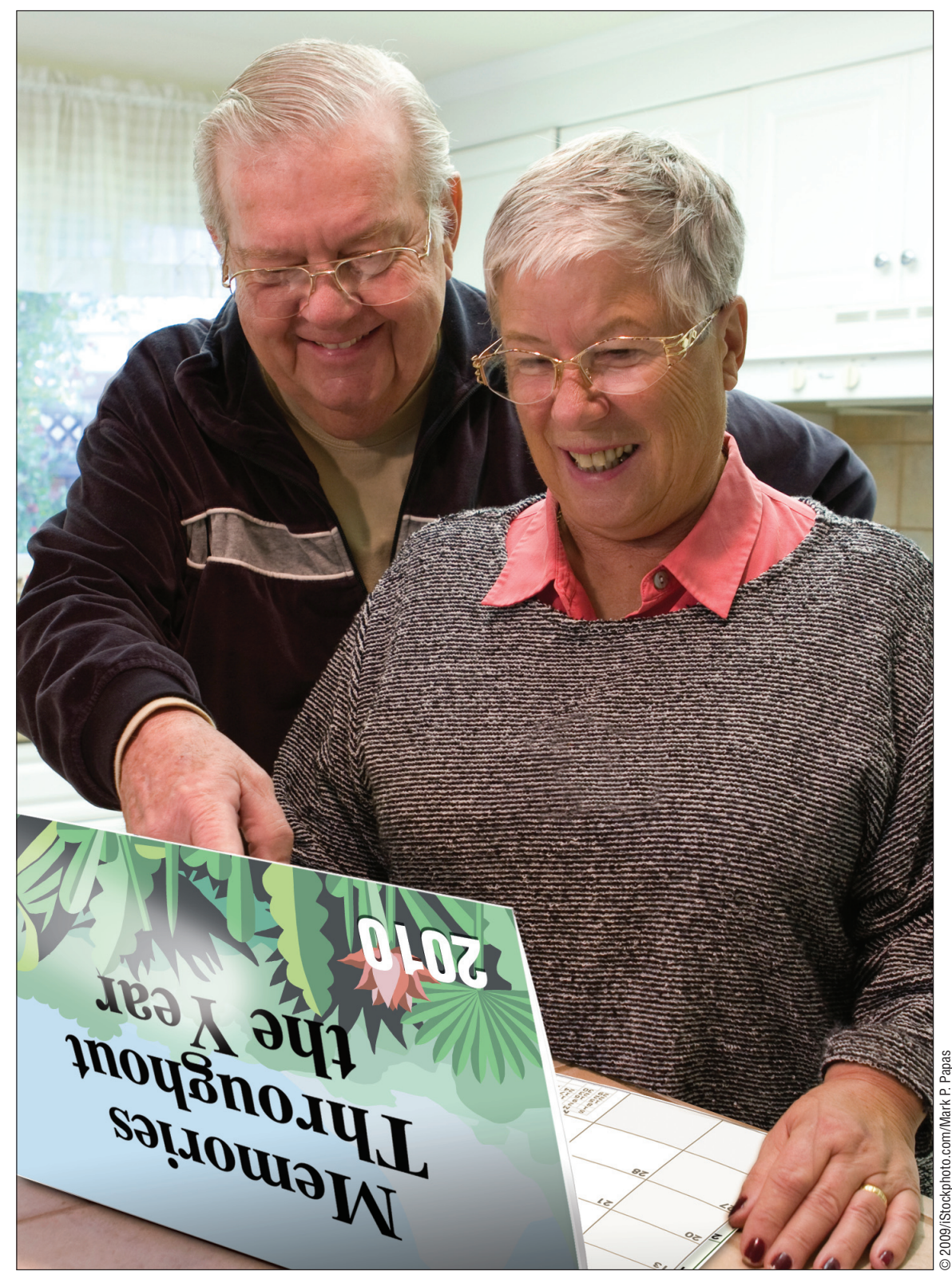

\section{ABSTRACT}

The purpose of this article is to describe a storytelling project that was designed to help community-dwelling older adults find meaning and purpose in their lives through reminiscing about the past. The storytelling project was successful not only for the older adults who participated but also for the nursing students, who were given an opportunity to learn about interviewing and communicating with older adults. The value of life review and storytelling as a nursing intervention became evident from this project. When time is taken to listen to the valuable stories and life lessons of the older population, nurses create a better understanding of their patients while their patients recall special memories and feel proud of their lives.

$\Lambda$ dults older than age $65 \mathrm{com}-$ prise a large percentage of the U.S. population and are estimated to reach $23 \%$ of the population by 2020 (Chiang, Lu, Chu, Chang, \& Chou, 2008). Because the number of older adults is increasing, it is important for nurses to become more familiar with the aging process and promote healthier aging. This includes promotion of not only a healthy lifestyle to sustain an aging body but also a healthy sense of self.

Katie Scott, BSN, RN; and Jacqueline Kayler DeBrew, PhD, APRN, BC 


\section{BACKGROUND}

Promotion of a healthy sense of self begins by taking into consideration Erik Erikson's theory of psychosocial development (Harkreader \& Hogan, 2004). According to E. Erikson, older adults enter the eighth and final stage of psychosocial development called ego integrity versus despair. To achieve integrity, older adults need to believe their lives have been productive with few regrets. This can be achieved by life reflection and acceptance. However, when integrity is not achieved, feelings of hopelessness and despair with a fear of death predominate (Harkreader \& Hogan, 2004). Even if despair, or "lost opportunities, meaninglessness, and failures" (Randers, Mattiasson, \& Olson, 2003, p. 290), wins the battle with integrity, the conflict may still be resolved. By tapping into their wisdom, older adults can recognize that they possess something to pass down to the next generation, and thus that their life has had meaning and purpose (Randers et al., 2003).

It is also necessary to take into consideration a ninth stage of psychosocial development for those age 80 and older, described by Erikson's wife, Joan. In this stage, it is believed that the very-old adult's greater dependence on caregivers and decreased ability to care for self, along with sorrow felt over the loss of abilities and loved ones, decreases the person's desire and energy level to reminiscence about life (Nilsson, Sarvimäki, \& Ekman, 2000). Therefore, it may be difficult for those who are very old to participate in life review. However, life review can promote meaning and purpose for older and very old adults so that ego integrity can be achieved. It is this meaning and purpose that this project set out to instill, through storytelling, in a group of older adults living in a senior housing facility. This article will describe the project and its usefulness to nursing students and educators.

\section{LITERATURE REVIEW}

\section{Life Review Group Program}

One kind of reminiscence, the Life Review Group Program (LRGP) (Chiang et al., 2008), has been proven to increase self-esteem and life satisfaction among older adults. LRGP consists of discussions about different aspects of a person's life, including memories from childhood and adolescence, the person's family, job, friends, and greatest accomplishments, with a final discussion to summarize the life review. Chiang et al. (2008) studied LRGP's usefulness in improving the self-esteem and life satisfaction of 75 older men living in a veterans' home. Participants in the experimental group experienced 8 weeks of this kind of life review program and were evaluated before, immediately after, and 1 month after the LRGP intervention. Results were compared to a control group who did not participate in the life review. The experimental group showed an increase in self-esteem on the Rosenberg Self-Esteem Scale, and had higher scores than the control group after the intervention. Life satisfaction scores, as measured by the Life Satisfaction Index scale, also increased in the experimental group (Chiang et al., 2008).

The LRGP improved participants' "sense of meaning and purpose in life" (Chiang et al., 2008, p. 9) because the program helped participants review and interpret their past and create a new positive outlook on the future. Therefore, it is important for older adults to feel a sense of purpose so their quality of life is improved (Chiang et al., 2008). With the knowledge that life review has been shown to improve self-esteem and life satisfaction among older adults, the nursing student who carried out this project (K.S.) hoped to accomplish the same outcome among the participants living in the senior housing facility. It was especially important to keep the goal of increasing life satisfaction due to the participants' lower socioeconomic status.

\section{Searching for the Meaning in Life}

Another kind of reminiscence involving focused themes and creativity has been shown to improve depressive symptoms among older adults. Searching for the Meaning in Life (Bohlmeijer et al., 2005) includes 12 group sessions, each lasting 2.5 hours and focused on a different theme. The sessions use creative ways to express memories; these may include stories, poems, or drawings. Researchers have studied the benefit of this intervention in improving depressive symptoms in a group of older adults (Bohlmeijer, Valenkamp, Westerhof, Smit, \& Cuijpers, 2005). Questionnaires were given before and after the intervention to measure participants' depressive symptoms. After the intervention, participants showed improvement on the depression scale, demonstrating that this kind of therapy can decrease symptoms of depression in older adults (Bohlmeijer et al., 2005).

The risk for depression among this project's participants is higher than in the general older adult population because of the participants' lower economic status. Older adults with low incomes are at increased risk for depression because they may be "living in deteriorated neighborhoods and having unstable housing, increased exposure to crime and victimization, poor nutrition, and poor physical health" (Areán, Gum, Tang, \& Unützer, 2007, p. 1057). These older adults are also at increased risk of not having their depressive symptoms treated because of the costs of and barriers to mental health care (Areán et al., 2007).

The nursing student knew at the beginning of the project that the participants were living in a housing facility for older adults with lower incomes; therefore, the student knew the participants were at risk for depression. Because reminiscence and creativity helped decrease symptoms of depression in Bohlmeijer et al.'s (2005) study, the nursing student hoped to decrease depressive symp- 
toms in a group that was already at increased risk. In addition, if the project turned out to be a useful intervention, it could be considered a cost-effective alternative for older adults with depression who have lower incomes.

\section{The Creativity Continuum}

Creative therapies, including life review and storytelling, are important in improving the health of older adults. The Creativity Continuum, as described by Sierpina and Cole (2004), uses three forms of storytelling to stimulate creative expression. The first storytelling intervention, Lifestory Workshops, allows participants to write and share personal stories in groups. This intervention
The nursing student took inspiration from the Lifestory Workshops and Visible Lives interventions when shaping the design of this project. Sharing with others is a major part of the Lifestory Workshops; sharing between the participant and the student was important in the design of this project. Through the displaying of the participants' stories on a wall calendar, the nursing student hoped to realize some of the same outcomes that have been achieved by the Visible Lives intervention.

\section{BENEFITS OF STORYTELLING}

Storytelling has positive outcomes not only for older adults, but for nurses as well. For nurses working with older adults to benefit from storytell-

\section{When time is taken to listen to the valuable stories and}

life lessons of the older population, nurses and nursing students create a better understanding of their patients.

has shown "increased well-being from participating in story writing and sharing" (Sierpina \& Cole, 2004, p. 176). Visible Lives is another intervention in which participants and interviewers create storyboards to publicly display personally important aspects of the participants' lives. After interviewing with a facilitator, the older adult works with the interviewer to create the storyboard that can include photographs, letters, and other personal items. The storyboard visualizes the adult's life and "assists in maintaining identity" (Sierpina \& Cole, 2004, p. 178) for the adult. TimeSlips, the third intervention, implements storytelling for people with dementia. All three kinds of creativity include storytelling and have been shown to increase activity and memory in participants and to be important interventions when working with older adults (Sierpina $\&$ Cole, 2004). ing, they "need to be given the permission to engage with older people" (Koch, Power, \& Kralik, 2007, pp. 6061). When given the opportunity to listen to older adults, nurses can begin to value them and decrease any negative stereotypes they may hold about this population (Koch et al., 2007). Clarke, Hanson, and Ross (2003) found that using storytelling allowed health care practitioners to "see the person behind the patient" and "build and strengthen relationships with patients and their relatives" (Clarke et al., 2003, p. 701). Hearing their patients' life stories enabled caregivers to see their patients as a whole person and form a greater bond with them. Storytelling also connected caregivers to their patients' families while caring for the patient and sometimes after the patient's death (Clarke et al., 2003). Storytelling has also shown to be a way to alter the relationship between patient and caregiver so the older adult is considered more important in making decisions about the care he or she receives (Pohlman, 2003).

Older adults often rely on nurses more as they age; therefore, it is important for nurses to have a positive attitude about aging and not hold ageist views. This can be accomplished by taking the time to listen to older patients' life stories and view the patient as an individual. For nursing students beginning to embark on a career in nursing, it is important to enter the profession without negative stereotypes about older adults. This project hoped to show that life review has implications for nursing curricula in helping nursing students decrease any negative feelings they may hold about the older population.

The promotion of meaning in health care professionals' lives is also of importance. Meaning for health care professionals can be described as something that "strengthens us, not by numbing our pain or distracting us from our problems, or even by comforting us. It heals us by reminding us of our integrity, who we are, and what we stand for" (Remen, 2001, p. 5). Meaning can be obtained by reverting back to the principles of service in which human relationships are of importance and distance between provider and patient should be minimal (Remen, 2001). Life review and sharing between nurses and patients can promote meaning and purpose not only in the lives of patients, but also in the professional lives of the nurses.

\section{THE PROJECT \\ Participants}

The purpose of this project was to help community-dwelling older adults find meaning and purpose in their lives through storytelling. A governmentassisted housing facility for individuals age 50 and older was chosen as the setting for this life review project. The facility has 221 apartment units for residents to live independently. This site was chosen because of its existing relationship with a local university's school of nursing. During school 
months, the nursing school holds a weekly wellness clinic for the residents. The 11 participants ( 10 women, $1 \mathrm{man})$ in this project were regular clinic participants. Their ages ranged from 57 to 77.

\section{Calendar Month Assignment}

Participants were assigned a month of the year to describe their memories, traditions, and thoughts related to their assigned month. Then, what they shared with the nursing student was to be displayed in a calendar presented to each participant at the end of the project. A calendar was chosen as the model for the project because it is practical, meaning that most people are familiar with the format of a wall calendar and can use a calendar throughout the year. In addition, memories are sometimes attached to months, seasons, or holidays. By giving each participant a month to talk about, the discussion between the student and participant was more focused to the topic of these associated memories. Finally, a calendar can be displayed in the home, allowing the participants to view their own month and their neighbors' months all year. The nursing student hoped this display would increase the pride the participants felt and thus their feelings of meaning and purpose.

A formal questionnaire was not used; instead, participants were asked: "What does this month mean to you?" and "Do you have any special memories about this month?" The participants then guided the interview through their stories, with the interviewer only asking questions as a way to gather more information. Participants were also given an opportunity to decide how their calendar month would look by sharing visual memories, such as describing the beach in the summer or reflecting on a childhood Easter shopping trip to New York City. One participant, however, chose to include her own drawings for her chosen month.

\section{KEYPOINTS}

\section{STORYTELLING}

Scott, K., \& DeBrew, J.K. (2009). Helping Older Adults Find Meaning and Purpose Through Storytelling. Journal of Gerontological Nursing, 35(12), 38-43.

1 The purpose of this project was to help community-dwelling

1 older adults find meaning and purpose in their lives through storytelling.

2 Participants were assigned a month of the year to describe their memories, traditions, and thoughts about the assigned month. Whatever participants shared was displayed in a calendar presented to each participant at the end of the project.

3 The storytelling project was successful in promoting meaning and purpose for the older adults who participated. It also gave the nursing student an opportunity to learn about interviewing and communicating with older adults.

4 The value of life review and storytelling as a nursing intervention is clearly evident from this project.

\section{Barriers to Participation}

There was some reluctance to participate in the project. Several people were not interested in participating, and many seemed distrusting of the project. This hesitation could have been related to past deceptions by strangers or fear of being taken advantage of due to their age, income, or living situation. There have been security issues in this housing facility, which may have further supported residents' distrust.

Some participants did not quite fall within the age dimensions of older adult. These participants may have been caught between stages seven and eight of Erikson's developmental stages. Stage seven of psychosocial development is generativity versus stagnation. To avoid stagnation, middle-aged adults need to feel that "life is personally satisfying and socially meaningful" (Harkreader \& Hogan, 2004 , p. 335). They focus on productivity and caring for others. However, if the adult reaches stagnation, egocentrism and self-absorption predominate (Harkreader \& Hogan, 2004). For participants falling into stage seven or in between the two stages, reflecting on their lives may not have been as important. It may have been more important for the participants to care for others and their own social needs, as well as attend to jobs and personal obligations. Also, they may not have reached the age in which the importance of life reflection is experienced; the younger participants may not have felt the need to pass on parts of their lives to others.

Time was also an issue with participants. Many did not participate because they did not have time to be interviewed. Originally, the nursing student had planned to meet with the residents for 45 minutes to 1 hour, but this time frame was shortened to 15 to 20 minutes to encourage more residents to participate. In addition, several wanted to think about what to say and prepare ahead of time, which was not always possible given the time constraints.

\section{FINDINGS}

Overall, participants seemed to enjoy participating in the project. Several laughed and smiled as they reminisced. Some chose to talk about specific memories, whereas others 
chose to talk more broadly about a time in their lives. Not all participants talked about the past, but rather shared family traditions and customs associated with that month.

After the interviews were completed, the nursing student put together a calendar with written depictions of residents' shared stories and images in accordance with their wishes about the appearance of their calendar month. An event was held in the clinic for the participants to receive their calendars and enjoy light snacks and socialization. Participants' reactions to the calendar at the social indicated their delight in sharing with others, happiness with the results, and overall pride in the product.

Several participants then began to share their calendar month with each other. They expressed interest in each other's stories by saying, "Which month did you have?", and proceeded to read the month together. One participant retold his entire story to another participant, which allowed him to remember not only what he had told the nursing student, but also more of the story details. This sharing with others allowed participants to reflect and remember parts of their lives and take pride in what they had to offer others. By reflecting and sharing, the participants could hold onto memories from long ago, so others could cherish them for years to come.

All of the participants seemed very happy with the calendar. Many were heard saying they "love it," and one said, "She [the nursing student] didn't leave out any details." The participants liked both their own calendar month as well as other participants' months. Their joy with the calendar and ability to see their memories and thoughts expressed in writing and pictures allowed them to feel proud. One participant said she wanted to frame the calendar and show it to her family. The project instilled the pride and sense of accomplishment that it set out to encourage.

The nursing student and the faculty member working with these par- ticipants in the wellness clinic also benefitted from this project. They formed relationships with and gained a deeper understanding of the residents. Getting to know the participants outside the clinic allowed the nursing student to form a bond with the participants, which increased rapport between the participants and the student in future clinic visits. The project also increased the visibility of the wellness clinic as other residents saw the completed calendars.

The nursing student also found that some of her preconceived ideas or stereotypes about older adults were broken as a result of getting to know the older adults on a more personal level. For example, the student was surprised to hear about some of the places to which the participants had traveled and the experiences they shared. In addition, as the student learned more about the participants, the participants began to trust the student more with medical issues at the wellness clinic. One participant approached the nursing student with a medical question that the participant had not shared all semester with other students at the clinic. A personal relationship was formed through the calendar project that allowed this older adult to feel more comfortable asking a question about her health status.

\section{CLINICAL IMPLICATIONS}

Interventions such as this project and other storytelling and reminiscence projects allow nurses to see older adults beyond the hospital bed and develop a better understanding of and rapport with their patients. Clearly, older adults enjoy talking about their lives and sharing with others. It is important, however, that they be given some freedom in what they choose to talk about. For example, some participants in this project did not have a specific memory they wished to share, so they were given the opportunity to talk about a month or a season in general. Anything they wished to share was welcomed. Because older adults are not homogeneous, not all will want to share the same kind of stories during life reviews.

For nurses hoping to implement a life review or storytelling intervention, it is helpful to allow the older adults time to reflect on and prepare what they would like to say. Nurses must take into account that older adults live busy lives, especially those in an independent living facility. They may not wish to spend long periods of time with the life review because of other obligations; therefore, several short meetings would be more beneficial.

Finally, as noted in the social event held at the completion of the project, older adults can greatly benefit from socializing and sharing with their peers. A group life review project may be instrumental in promoting meaning and purpose. Instead of meeting individually with participants, nurses could hold group meetings in which everyone shares stories and memories together.

It is hard to know whether the effects were sustained for the participants after completion of this project because the clinic closed at the end of the semester, and the nursing student did not have any further contact with the participants. However, because the calendar can be displayed all year, it is hoped that the participants' feelings of pride and accomplishment were felt all year long. For the nursing student, the effects were sustained. The student's ideas about older adults were changed, and the student is now more comfortable talking with older adults. The value of life reflection as a nursing intervention has also been instilled for the student. She can eventually use what was learned during the project as a new graduate nurse. This student will be working in an intensive care unit (ICU) after graduation and plans to use life review with patients who are able to verbally communicate in the hopes that their anxiety levels from being in the ICU will decrease. In addition, the student plans to use 
life review with patients' families so family members can pass on the life stories of their loved one, especially in end-of-life situations.

\section{SUMMARY}

This storytelling project was successful in promoting meaning and purpose for the older adults who participated. The project also gave the nursing student an opportunity to learn about interviewing and communicating with older adults. The value of life review and storytelling as a nursing intervention is clearly evident from this project. When time is taken to listen to the valuable stories and life lessons of the older population, nurses and nursing students create a better understanding of their patients, and the older adults recall special memories and feel proud of their lives.

\section{REFERENCES}

Areán, P.A., Gum, A.M., Tang, L., \& Unützer, J. (2007). Service use and outcomes among elderly persons with low incomes being treated for depression. Psychiatric Services, 58, 1057-1064.

Bohlmeijer, E., Valenkamp, M., Westerhof, G., Smit, F., \& Cuijpers, P. (2005). Creative reminiscence as an early intervention for depression: Results of a pilot project. Aging $\mathcal{E}$ Mental Health, 9, 302-304.

Chiang, K.J., Lu, R.B., Chu, H., Chang, Y.C., \& Chou, K.R. (2008). Evaluation of the effect of a life review group program on self-esteem and life satisfaction in the elderly. International Journal of Geriatric Psychiatry, 23, 7-10.

Clarke, A., Hanson, E.J., \& Ross, H. (2003). Seeing the person behind the patient: Enhancing the care of older people using a biographical approach. Journal of Clinical Nursing, 12, 697-706.

Harkreader, H., \& Hogan, M.A. (2004). Fundamentals of nursing: Caring and clinical judgment (2nd ed.). Philadelphia: Saunders.

Koch, T., Power, C., \& Kralik, D. (2007). Researching with centenarians. International Journal of Older People Nursing, 2, 52-61.

Nilsson, M., Sarvimäki, A., \& Ekman, S.L. (2000). Feeling old: Being in a phase of transition in later life. Nursing Inquiry, 7, 41-49.

Pohlman, B. (2003, October 1). Storytelling circles: Stories of age and aging. Generations, pp. 44-48.

Randers, I., Mattiasson, A.C., \& Olson, T.H. (2003). The "social self": The 11th category of integrity-Implications of enhancing ge- riatric nursing care. Journal of Applied Gerontology, 22, 289-309.

Remen, R.N. (2001). Recapturing the soul of medicine: Physicians need to reclaim meaning in their working lives. Western Journal of Medicine, 174, 4-5.

Sierpina, M., \& Cole, T.R. (2004). Stimulating creativity in all elders: A continuum of interventions. Care Management Journals, 5 , 175-182.

\section{ABOUT THE AUTHORS}

$M s$. Scott is a BSN graduate, and Dr. DeBrew is Clinical Associate Professor, University of North Carolina at Greensboro, School of Nursing, Greensboro, North Carolina.

The authors disclose that they have no significant financial interests in any product or class of products discussed directly or indirectly in this activity, including research support.

Address correspondence to Jacqueline Kayler DeBrew, PhD, APRN, BC, Clinical Associate Professor, University of North Carolina at Greensboro, PO Box 26170 , Greensboro, NC 27402-6170; e-mail: jkdebrew@uncg.edu.

Received: March 15, 2009

Accepted: August 4, 2009

Posted: November 23, 2009

doi:10.3928/00989134-20091103-03 
Copyright of Journal of Gerontological Nursing is the property of SLACK Incorporated and its content may not be copied or emailed to multiple sites or posted to a listserv without the copyright holder's express written permission. However, users may print, download, or email articles for individual use. 